\title{
Ensino de desenho e habilidade espacial no conceito de Gildo Montenegro
}

\section{Lilian Quelle Santos de Queiroz}

Doutorado; Professora Adjunto; Universidade Estadual de Feira de Santana UEFS; lilian@uefs.br

\section{RESUMO:}

Este texto buscou redigir sobre a experiência oportunizada pela docência de Desenho no âmbito da graduação da Universidade Estadual de Feira de Santana, na Bahia, e em diferentes cursos percebendo a noção de representação e o desenvolvimento da habilidade espacial segundo o conceito de Gildo Montenegro que pode ser ensinado pelo estímulo da Imaginação Espacial, nos mais diferentes níveis, quer seja ensino fundamental, médio ou graduação no qual uma vez que o papel da escola na condução de seu trabalhos passa por pensar criticamente, viver criativamente, decidir livremente e agir eticamente. Constatamos que, como relata Gildo em seu livro sobre a Inteligência visual e 3-D, as lacunas oportunizadas pelo déficit de ensino de desenho ao longo da formação, acompanham os estudantes até a graduação e tende a dificultar a percepção espacial dos educandos. Para tanto, relatamos a experiência ocorrida em quatro turmas de Desenho técnico, por dois semestres consecutivos com alunos do Curso de Engenharia Civil para investigar o modo como o Desenho está presente em sua trajetória de aprendizado e como eles percebem que este pode influenciar em suas proposições profissionais e sua formação como um todo, quer seja de ordem pessoal, emocional ou técnica.

Palavras-chave: Desenho; Percepção; Habilidade Espacial. 


\section{INTRODUÇÃO}

Ministrando aulas para os Componentes Curriculares de Desenho em variados cursos no âmbito da Graduação da Universidade Estadual de Feira de Santana-UEFS na Bahia, a segunda cidade mais populosa do estado ${ }^{1}$, dentre eles Matemática, Pedagogia, Letras e Engenharia, se pôde notar a resistência em perceber o Desenho enquanto potencial expoente para o desenvolvimento da visualidade da expressão humana, quer seja esta de ordem, técnica, artística ou científica, como a Geometria projetiva, Desenho de Observação e a Ilustração científica respectivamente como exemplos das notações anteriores.

Partindo desse princípio, do Desenho enquanto promotor do desenvolvimento da inteligência espacial e entendendo essa como uma habilidade passível de ser desenvolvida por todos os indivíduos (MONTENEGRO 2005), buscou-se investigar de que modo os alunos que cursam as disciplinas de Desenho percebem a relevância deste percurso para o seu processo de formação, pessoal e profissional e de que modo essa percepção pode ser, de alguma maneira mensurada.

O Professor Gildo Montenegro atribui a dificuldade em desenvolver e utilizar a habilidade espacial ao ato de ensino precário da geometria nas instituições formais de educação, tanto para o fundamental quanto para o nível médio (MONTENEGRO, 2005) e por conseguinte na graduação essa aspecto se amplia. 0 que foi observado ao longo dessa pesquisa é que os alunos trazem consigo uma resistência ao aprendizado de Desenho, de modo geral sendo egressos de instituições públicas ou provadas de ensino, fato este que dificulta ainda mais o entendimento das possibilidades de percepção que este estudo/aprendizado tem a oportunizar.

Outra atribuição de Gildo Montenegro (2005) para a dificuldade apontada, recai sobre os métodos de ensino adotados pelos docentes na área do desenho, que por muitos motivos como a grade curricular, a pretensa formação profissional ou a falta de tempo para cumprir todos os conteúdos previstos que abordem o uso e a percepção sobre Desenho, a abordagem negligencia o repertório do indivíduo bem com a sua intuição espacial.

Para essa pesquisa foi realizado um acompanhamento anual, por dois semestres letivos regulares, 2016.1 e 20171. Com os alunos de engenharia Civil da UEFS, totalizando um universo de das quatro turmas composta por 80 alunos, dispostos em duas turmas uma com 22 alunos e outra com 21 alunos no em 2016 e uma turma de 16 e outra com 21 em 2017.

Através das atividades propostas sob o pretexto de aplicação prática dos conteúdos teóricos, bem como a análise destes a luz das perspectivas de Gildo Montenegro (2005), Mário Duarte Costa (1996) e Sérgio Murilo Ulbricht (1998), observamos a resposta dos discentes em relação a abordagem que

\footnotetext{
${ }^{1}$ Esta lista de municípios da Bahia por população está baseada na estimativa de 2017 do IBGE - Instituto Brasileiro de Geografia e Estatística. A Bahia é uma das 26 unidades federativas do Brasil e é dividida em 417 municípios. Acesso em «estimativa_ibge_2017.xls». agenciadenoticias.ibge.gov.br. Consultado em 30 de agosto de 2017.
} 
envolve o Desenho bem como o desenvolvimento de suas habilidades espaciais.

\section{DO QUE SE TRATA O ENSINO DE DESENHO}

Iniciamos essa reflexão demonstrando o pensamento de alguns autores que dialogaram com essa pesquisa sobre o estudo e ensino de desenho e de que modo estes devem ser estabelecidos a fim de alcançar o desenvolvimento de suas habilidades em sua mais extensa forma por meios de técnicas e abstrações, a saber percepção visual e a noção de espacialidade. Partimos do pressuposto que de o aprendizado em Desenho, requer como todo método de ensino, uma sistemática mínima a fim de se obter o resultado almejado.

Pra que desenhar? Por que desenhar? e para quem desenhar? São as primeiras questões que emergem quando pensamos na relação de ensino e aprendizagem em Desenho. Estaria sendo falado sobre Desenho Técnico, Artístico ou Científico? É o que vai determinar a intencionalidade do efeito técnico construtivo do Desenho. 0 mais relevante nessa reflexão é que independente das respostas as perguntas do início do parágrafo, a experiência que a construção em desenho oportuniza extrapola os limites da expressão gráfica.

Ainda assim para começar a desenhar, não é preciso muitos materiais, o que facilita o registro gráfico após o pensar, segundo Bismarck (2000). “0 desenho então institui-se como um espaço privilegiado de investigação, no desemaranhar dos fios do pensamento, em que, desenhar é como clarificar os passos, percursos e estratégias da nossa consciência, trazendo-os à superfície do suporte." (BISMARCK, 2000, p.01). É isso que torna o desenho mais prático que a escultura ou pintura, por exemplo, deixando seu uso mais eficaz no momento em que se deseja "formar sentidos e visualizar caminhos" (BISMARCK, 2000, p.02). Ou seja, o desenho traz à tona o que nossa consciência gostaria de materializar. É uma forma de desembaralhar os muitos pensamentos que passam pela mente do ser humano, seja o desenho compreensível a outro ou apenas à própria pessoa.

O desenho está presente em toda a vida de um ser humano, seja ele o desenhista ou não. 0 contato com o desenho começa com a criança em seus primeiros esboços do modo como enxerga as pessoas. A partir daí se intensifica ao entrar na escola, onde há desenho em praticamente tudo para que ela possa aprender a higienização do corpo, o caminho da sala, as comidas, comportamentos adequados, enfim, aprender a viver em sociedade, além de estar frequentemente praticando o desenho para estimular a imaginação e assimilar todo o aprendizado. A partir daí, o desenho vai se tornando mais complexo durante a vida escolar da criança, a fim de proporcionar a visualização das imagens necessárias para assimilação do conteúdo.

Quando refletimos junto ao contexto histórico da instituição de ensino de desenho nos deparamos com uma forma estruturada, como nos diz Ulbricht 
(1998), de local de aprendizado está condicionado ao local onde se trabalha. 0 autor nos diz que:

No Brasil, a maioria dos profissões dos obreiros da construção civil como mestres, carpinteiros, pedreiros, armadores de ferro, azulejistas e até mesmo profissões eu exigem um maior preparo técnico como as de eletricista e encanador também são aprendidas em muitos casos, no próprio canteiro de obras. 0 mesmo acontece com frequência com a profissão de desenhista, nos escritórios de desenhos das fábricas, das empresas de publicidade e escritórios de engenharia e arquitetura. (Ulbricht, 1998, p.14)

Nesse sentido existia uma preocupação com a formação daqueles que certamente iriam transmitir as futuras gerações os saberes apreendidos, herança europeia costume do século XIV Anos mais tarde, as instituições de ofícios foram ganhando corpo e no Brasil, com a criação da Real Academia Militar de D. João VI, e por conseguinte o início do ensino de Geometria Descritiva, foi se estabelecendo uma maneira de ensino de desenho ligada a funcionalidade e ao profissionalismo técnico dos aprendizes Ulbricht (1998).

Segundo Costa, essa proposição formativa não compreende o todo relativo as potencialidades dos indivíduos. O que Costa (1996) propõe é um estudo no qual revele a possibilidade de aprendizado em sua totalidade, em seus múltiplos aspectos para que, a partir desse ponto, com todo o arcabouço exibido para o ensino, o educando possa extrair o potencial criativo desse aprendizado, segundo sua proposta de entendimento de ensino:

Comparemos o desenho a um idioma. Este possui uma gramática. Para bem se explicar no idioma, seja compondo uma obra literária, ou escrevendo um relatório técnico ou ainda elaborando uma tese científica, o autor da mensagem deve ser entendido por aqueles que irão recebe-la. (...) 0 Desenho igualmente permite uma finalidade artística, técnica ou científica, tem sua gramática justamente nas técnicas de representação gráfica. Mas assim como não aprendemos o idioma apenas estudando as regras de sua gramática, sem praticar sua leitura e escrita, também não dominamos a linguagem do desenho apenas com o estudo da geometria. Também pretender aprender desenho sem desenhar é tão absurdo como aprender a ler sem escrever. (COSTA, 1996, p.13)

Através dessa proposição o autor nos aponta que deve existir uma dinâmica de aprendizado voltada para o Desenho que elenque suas potencialidades e desenvolva por sua vez uma espécie de letramento sobre o que é o Desenho e para que se propõe ensiná-lo. De certo modo, conforme nos revela o autor, sem esse pensamento e organização prévias de seleção de conteúdo e elaboração de atividades voltadas para esse fim, o ensino de Desenho cai num vazio abissal do desinteresse dos alunos pelo aprendizado de desenho.

Essa falta de interesse pelo desenho repercute em uma certa precariedade na compressão de um aspecto imprescindível na orientação e organização do desenho que é a linguagem visual que o Desenho envolve, transborda, compete. Sem esse entendimento, a linguagem que o Desenho tende a transmitir certamente não alcançara seu objetivo. 
Na tentativa de alcançar uma leitura crítica da realidade e desenvolver a habilidade visual através das representações que o desenho comunica, a possibilidade que visa colaborar nesse intento diz respeito

\begin{abstract}
A linguagem visual constitui a base de criação do desenho. Deixando de lado o aspecto funcional do desenho, há princípios, regras ou conceitos, com relação à organização visual que podem preocupar um desenhista. Ele pode trabalhar sem o conhecimento consciente de quaisquer destes princípios, pois seu gosto pessoal e sensibilidade com respeito às relações visuais são muito mais importantes, porém uma compreensão completa destes definitivamente ampliaria a sua capacidade de organização visual. (WONG, p.41, 1998)
\end{abstract}

Desta forma, corroborando com o aspecto formativo, o qual destaca Costa (1996), como sendo este aspecto fundamental para o estímulo do desenvolvimento da habilidade espacial que o discente possui enquanto característica inerente ao ser humano, e que, necessita ser otimizada através da organização e apreensão da linguagem visual que o desenho visa transmitir.

Atrelado ao aspecto formal os alunos estão sujeitos ainda a uma cobrança de aprendizado no sentido de apresentar uma técnica perfeita, um esboço bem acabado, em detrimento de explorar a sensação do processo de desenhar como um todo. Philip Hallawell (2006) nos chama atenção para um aspecto fundamental no processo construtivo do desenho quando afirma que:

\begin{abstract}
0 desenho também desenvolve a expressão a sensibilidade e a intuição. Para quem está desenhando, é o processo no qual está envolvido que é importante, e não o produto que resulta desse processo. Para o artista, o prazer está no fazer da obra, e não na obra produzida. Para o aluno é importante lembrar isso, porque não se deve preocupar com o desenho acabado, mais com o processo de aprendizado e descobrimento. 0 aluno deve se preocupar com o entendimento e o domínio dos elementos que formam uma obra de arte visual, e aí o produto será uma consequência natural desse domínio. (HALLAWEL, 2006, p.12)
\end{abstract}

0 que o autor ressalta se concentra pois, no papel fundante que o processo de construção do desenho oportuniza ao indivíduo que o produz, e, nesse sentido, salientamos ainda que esse percurso, aliado ao repertório dos discentes se converte em terreno fecundo para o desenvolvimento da habilidade espacial.

Discorrendo ainda na recorrente variação de intencionalidade e modo de execução ligadas ao Desenho artístico e ao Desenho Técnico, detectamos vários manuais práticos com dicas, normas e modos de fazer o operacionalizar desenho. 0 que temos que atentar diz respeito ao processo de mecanização que pode incorrer a produção de desenho. Montenegro (2005) destaca enquanto relevante sobre o ensino nos chama atenção para o fato de que:

Os guias os roteiros as tabelas, os métodos e as regras afastam o pensamento da linha intuitiva da imaginação. 0 que se costuma ver é a total inadequação de muitas estratégias lógicas ou mecânicas para resolver problemas, porque elas esquecem a inteligência, a intuição, a imaginação, a perspicácia. (...) Educar leva um tempo e, 
talvez a pressa leve muitas instituições a dar/ensinar ao jovem coisas úteis para uma profissão. Estas instituições atendem as primeiras necessidades, mas não são instituições de formação. Uma pessoa ou sociedade, sem inteligência tende a imitar pensamentos e importar atitudes. A inteligência é crucial e a aprendizagem é para a vida humana, tanto no aspecto pessoal como no profissional. (MONTENEGRO, p.74-75,2005)

$\mathrm{O}$ autor Paulo Freire se reportava ao ato de ensinar como sendo um ato "essencialmente político", que por sua vez assim sendo, é dotado de intencionalidade se os professores não intuírem a intencionalidade de voltar o aprendizado de desenho para além dos muros do tecnicismo, essa resistência por parte de aprender e aguçar a espacialidade visual dos educandos não alcançara êxito, menos ainda se propagará.

\section{PROPOSTA DE INVESTIGAÇÃO E ANÁLISE DOS DADOS}

Tendo elencado as turmas para estudo, após análise dos conteúdos apropriados a disciplina ligados ao desenho de Elementos Estruturais, a instalações Hidrossanitárias e Instalações Elétricas, conteúdos que integram o programa da disciplina, o primeiro questionamento, me colocando na posição dos discentes seria sobre o que representar nesse quesito em relação ao desenho técnico. 0

Levando em consideração que os alunos já tiveram o contato com outras disciplinas ligadas ao Desenho Técnico como Desenho Básico, Geometria Descritiva e Desenho Arquitetônico, entende-se que já se possui um contato prévio com o uso de instrumentos e com a visualidade espacial necessária para compreensão dos aspectos hora não visíveis, como arestas e contornos existentes em segundo plano, conforme imagens a seguir:

Figura 1: proposição de atividade prática para aula de Desenho Técnico.

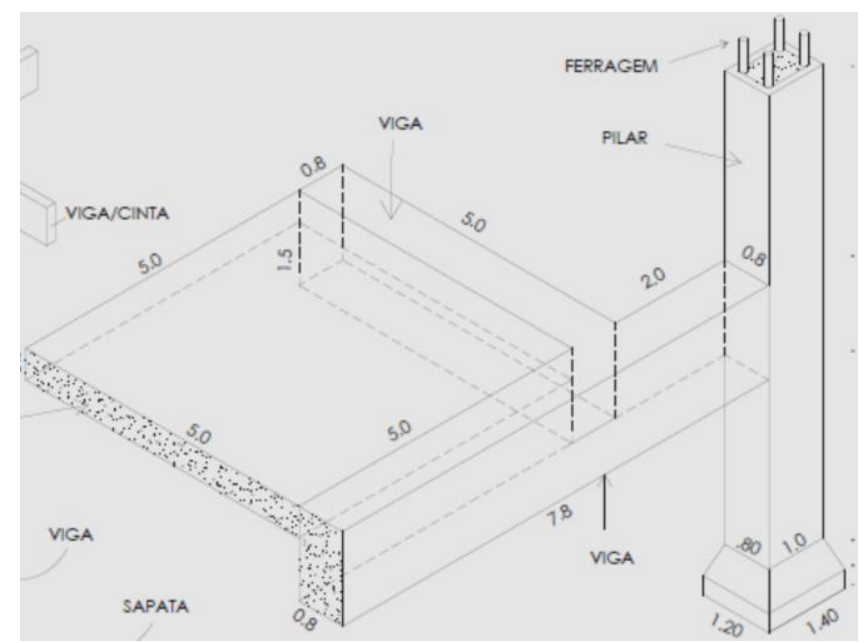

Fonte: Acervo pessoal, (2017) baseada no livro CHING, Francis, D. K. Técnicas de Construção ilustradas. Tradução Técnica:Alexandre Salvaterra. 4ªEd. Porto Alegre: Bookman, 2010. 
Figura 2: proposição de atividade prática para aula de Desenho Técnico.

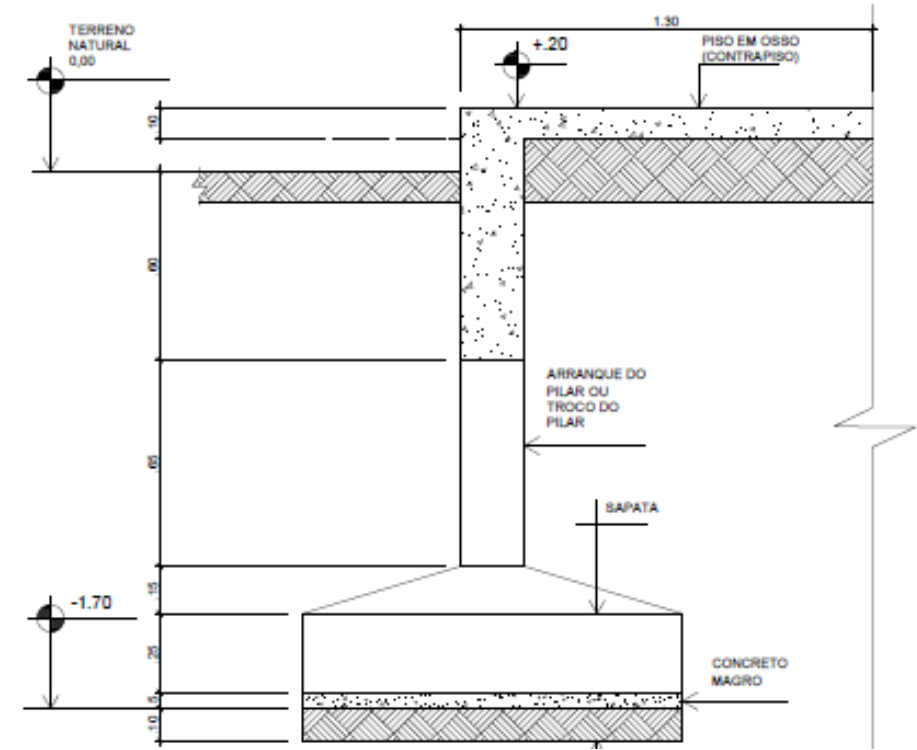

Fonte: Acervo pessoal das aulas da Dsiciplina LET 617-E (2017)

Foi realizado um levantamento inicial, repetido em todas as turmas, com questionamentos sobre que visão os alunos tinham sobre o ensino de Desenho técnico e a importância que eles julgavam que este ofertasse para a engenharia; se já haviam realizado atividades relacionadas ao Desenho Técnico fora do âmbito da universidade; se tinham contato com os programas de desenho assistidos por computador e por fim se já haviam atuado profissionalmente na área da engenharia e em caso positivo o que o desenho teria ofertado de contribuição.

Do total da amostra elegida, 75 por cento dos alunos, ou seja 60 do total, entendiam inicialmente que o desenho técnico se restringia ao uso repetido das ferramentas assistidas por computador. Partindo dessa informação e aliando o estudo dessas ferramentas, de inegável valor para o desenvolvimento técnico do Desenho, lhes foi advertido de que o trabalho nas pranchetas seria utilizado e tão valoroso quanto o trabalho que poderia ser desenvolvido pelo auxílio do computador. Naturalmente houveram resistência por parte desse referente, mais com a continuidade das atividades esses questionamentos forram sendo debelados e a participação foi ativa de todos.

Especificado o campo de pesquisa e o universo de 80 alunos dos cursos de Engenharia Civil da UEFS e baseado na classificação proposta por Ulbritch (1998) para estudos do trabalho que, segundo o próprio autor e baseados nos estudos de Cifuentes $(1995)^{2}$ também podem ser usados para

2 CIFUENTES apud ULBRITCH (1998) - Bibliografia referenciada: CIFUENTES, Purificacion. La representation de I'espace dans I 'apreentissage du dessin technique. Louvais -la -Neuve, 1995. Thèse presentée pour le doctoralt de Iúniversitè Catholique de Louvain. Psychologie et des Sciences de Iéducation. 
estudos relativos a produção de desenho, observamos durante o processo três tipos básicos de representações mais utilizadas:

O primeiro tipo é chamado de estudos prescritivos. Estes dizem respeitos a desenho que são feitos manualmente, baseados em normas específicas e que não denotam o envolvimento do sujeito no processo de trabalho. (ULBRITCH, 1998, grifo nosso); O segundo tipo de desenho identificado diz respeito aos que se agrupam no chamados estudos empíricos está ligado ao processo de realização do desenho em si, os esboços, cálculos, a consulta aos livros, mais ainda assim não reportam com especificidade a experiência do desenhista para execução do trabalho. (ULBRITCH, 1998, grifo nosso); 0 último diz respeito ao desenhos identificados no grupos chamados e estudos experimentais, nesse caso são evidenciados os dados sobre a produção do desenho. (ULBRITCH, 1998, grifo nosso).

Atrelando a teoria apresentada por Ulbritch as experiências com Desenho ocorridas nas turmas de Desenho Técnico, encontramos os três tipos supracitados de estudos dispostos a saber:

Tabela 1: Quadro sintese com as atividades correlacionando-as com a teoria apresentada por ULBRITCH (1998)

\begin{tabular}{|c|c|}
\hline $\begin{array}{c}\text { Estudos } \\
\text { Prescritivos }\end{array}$ & $\begin{array}{r}\text { Nessa etapa, as atividades propostas estão baseadas nas Normas da } \\
\text { ABNT e na Bibliografia Técnica Especifica; }\end{array}$ \\
\hline $\begin{array}{c}\text { Estudos } \\
\text { Empíricos }\end{array}$ & $\begin{array}{c}\text { Nessa fase, as atividades propostas estão baseadas em etapas } \\
\text { especificas, ligada a leitura, criação e interpretação dos projetos de } \\
\text { Desenho técnico; }\end{array}$ \\
\hline $\begin{array}{c}\text { Estudos } \\
\text { Experimentais }\end{array}$ & $\begin{array}{c}\text { Nesse aspecto o relevante é que o aluno realize seu processo de } \\
\text { apreensão do conteúdo baseado na própria experiência. }\end{array}$ \\
\hline
\end{tabular}

Fonte: Acervo pessoal produzido pela autora (2017), baseado na perquisa empirica e na teoria apresentada por ULBRITCH (1998)

Com estas divisões, especificadas em tipos diferenciadas de atividades, podemos observar o modo como o comportamento e o aprendizado de cada aluno em relação as proposições que eram abordadas. Inicialmente, com a etapa dos Estudos Prescritivos, as atividades eram realizadas sem maiores questionamentos de formatação, uma vez que as Normas ditam as regras de composição e configuração dos desenhos. Os discentes foram solicitados a elaborar exercícios que enfatizavam a parte técnica embasados nos pressupostos teóricos legitimados dentro da estrutura técnica do desenho.

$\mathrm{Na}$ fase dos estudos empíricos, a proposição visava orientar no sentido de seguir as etapa previamente orientadas, como a consulta das Normas específicas e bibliografias especializadas, o discurso teórico sobre o 
tema, posteriormente o desenho inicial em linhas de construção e em seguida os demais processos como cotagem e valorização dos pontos principais do desenho.

$\mathrm{Na}$ fase dos estudos experimentais, destacamos o contato inicial dos discentes com os exercícios e proposições didáticas anteriores a explanação teórica, no sentido de proporcionar a experiência de criar as dúvidas e a partir delas iniciar as aulas de teoria já com uma experiência prévia dos alunos, sobretudo na parte de instalações elétricas onde eles intuitivamente realizavam um dimensionamento inicial para posteriormente entender as etapas eu envolvem o processo.

Quanto as respostas aos questionamentos realizados, levando em consideração que todos tinham a liberdade em responder e não responder a esses questionamentos, uma vez que não figurava enquanto conteúdo da disciplina, logo todos foram consultados afim de expressar suas opiniões, elaboramos um quadro que revela a impressão das turmas consultadas no período supracitado, conforme demonstra o gráfico a seguir:

Gráfico 1: Comparativo entre as respostas fornecidas pelos discentes (2016-2017)

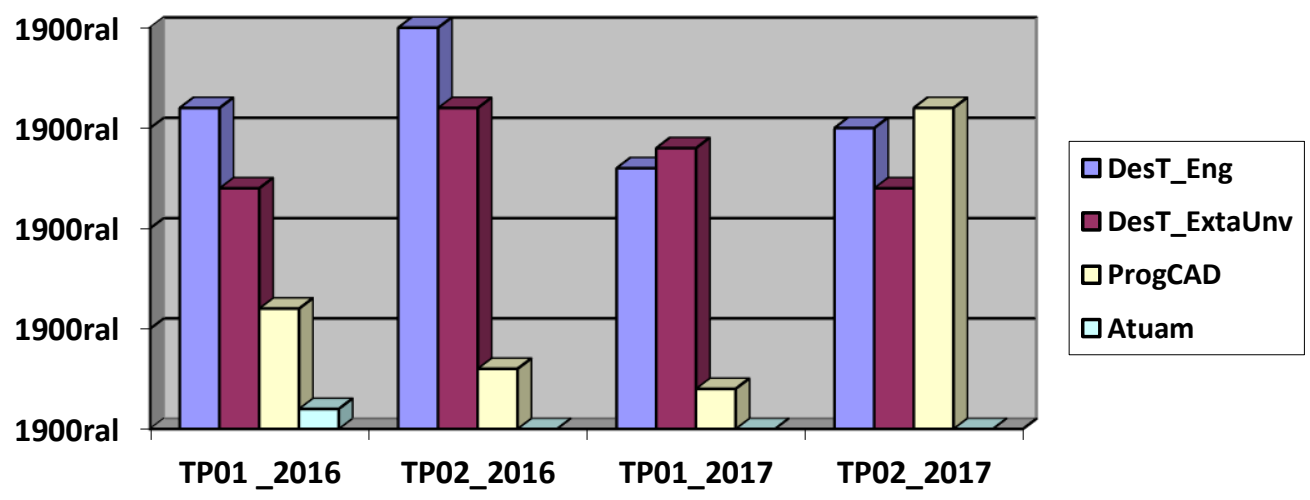

Fonte: Acervo da pesquisa

Sobre as respostas que a pesquisa obteve podemos elencar alguns aspectos relevantes e que sugerem uma aproximação com a proposta de Montenegro (2005) de desenvolvimento de habilidade espacial pelos discentes através do ensino de desenho. Notadamente, ainda que com uma oscilação nas turmas no tocante a variação de relevância, uma amostra representativa de cada classe observou q importância do desenho para a engenharia, fator que se deve ainda pelo fato dos discentes possuírem outras disciplinas ligadas ao desenho e a partir desta constatação, já trazerem uma certa percepção para esse intento.

Quando inqueridos sobre já ter realizado atividades de desenho fora do âmbito da universidade, esse número ainda se mantém expressivo, levando em consideração ainda que não foi especificado que tipo de atividade foi realizada e nem em que nível de formação ocorreu essa experiência. 
Uma outra constatação observada se refere ao fato de que a maioria almeja manipular programas de computador mais que na realidade não tinha acesso aos mesmo e ainda assim, não desejavam utilizar os materiais técnicos para desenvolver os trabalhos propostos em sala de aula, realizando motivados pela avaliação que se seguia após o término de cada bloco de conteúdo. 0 passar dos anos foi indicando a necessidade do contato com os programas de comutador, incipiente no início da pesquisa, que por sua se revelou expressivo no ultimo semestre

A pergunta que segue diz respeito a atuação na área de curso, aqui também pelo fato de muitos ainda estarem se estabelecendo no quinto semestre do curso ainda não tiveram oportunidade para estágio e nem cursaram outras modalidades de curso que trabalhassem o desenho. Apreendemos através desse aspecto que, diferente do passado onde as técnicas eram aprendidas nos locais de trabalho, a necessidade hoje é que o discente, futuro profissional já domine minimamente as técnicas dos programas para desenho assistidos por computador.

\section{CONSIDERAÇÕES FINAIS}

Pensar em Desenho perdurou no imaginário coletivo durante muitos anos como um momento dedicado ao ócio sem propósito definido ou ao ocupacionismo exclusivamente. Nas últimas Décadas, os encontros nacionais e internacionais sobre desenho e expressão gráfica e pesquisadores da área veem demonstrando que pensar Desenho transpõe barreiras para além da reprodutibilidade técnica, fazendo uma alusão a reflexão de Walter Benjamim, da falta de intencionalidade e da ocupação disciplinar a qual estamos habituados a nos deparar. Talvez esteja nesse o motivo pelo qual existe tanta dificuldade em estabelecer um conceito fechado para o que entendemos por Desenho.

Quer seja desenho à mão livre, técnico, intuitivo ou assistido por computador a experiência oportunizada pela contato com o desenho tem sido deixada a margem em detrimento de uma produtividade acelerada cujo único intuito é fornecer mão de obra para o mercado de trabalho sem levar em conta a formação do indivíduo critico, dotado de habilidades espaciais.

Se pôde perceber que o ensino de Desenho Técnico nas Universidades está cada vez mais atrelado aso programas de computador. 0 que seria uma consequência no aprendizado em desenho torna-se cada vez mais elemento fundante do princípio de aprendizado.

Em consequência desse processo de desvalorização do desenho, foi deixada de lado toda experiência legada ao desenvolvimento e compreensão das habilidades espaciais que os indivíduos possuem e que nem sempre são estimulados a utilizar. 0 papel do desenho fica em segundo plano nessa perspectiva.

Dado o histórico de desenho ligado a funcionalidade e ao desenvolvimento tecnicista, ressaltar que uma habilidade no âmbito da 
representatividade e da habilidade visual, partem pois desse contato com o desenho é levantar uma perspectiva de entendimento para além dos muros da universidade, é, pois, refletir em um processo de formação humana como um todo, a partir da experiência da percepção e da representação, além de desenvolver uma noção de espacialidade agregada ao ensino de desenho.

Constatou-se ainda que com o advento dos programas de computadores para elaboração de desenho que inicialmente constituía-se como um rival para a estrutura de desenho manual, tende a caminhar nas proximidades uma vez que a visualidade de computador e da ação humana transpõem aspectos diferentes, ou seja, dimensões diferentes da atuação e percepção humana.

Apesar de historicamente o ensino de desenho estar ligado a constituição técnica, e não ter se afastado por completo dessa premissa, o experiência em desenho visa oportunizar o desenvolvimento das habilidades especificas ligadas a visão espacial e a representação, através do domínio dos seus códigos e símbolos que compõe sua linguagem específica.

\section{REFERÊNCIAS BIBLIOGRÁFICAS}

BISMARK, Mário. Desenhar é o Desenho. [online] Homepage: https://repositorio-aberto.up.pt/handle/10216/19089. 2000. Consultado em $30 \mathrm{de}$ julho de 2017

COSTA, Mário Duarte. Geometria Gráfica Tridimensional. Recife. Editora Universitária UFPE, 1996.

FONTOURA, Ivens. Decomposição da Forma. Manipulação da Forma como instrumento para a criação. Coleção forma e Cor. Editora Itaipu, 1982.

HALLAWELL, PHILIP, À mão livre. A linguagem e as técnicas do desenho. São Paulo: Editora Melhoramentos, 2006.

MONTENEGRO, Gildo. Inteligência Visual e 3-D. Compreendendo conceitos Básicos da Geometria Espacial. Editora Edgar Blucher, 2005.

ULBRITCH, Sérgio Murilo. Geometria e Desenho: História, pesquisa e Evolução. Florianópolis, 1998.

WONG, Wucius. Princípios da Forma e do Desenho. Tradução Alvamar Helena Lamparelli. São Paulo: Martins Fontes, 1998.

CARVAlHO, G. L. Ambientes Cognitivos para Projetação: um estudo relacional entre as mídias tradicional e digital na concepção do projeto arquitetônico. 260f. Tese (doutorado) - Universidade Federal de Pernambuco. CAC. Desenvolvimento Urbano, 2004.

\section{AGRADECIMENTOS}

Agradeço aos alunos da turma de Desenho Técnico - E pela acolhida em sala de aula, nas respostas e participação da pesquisa e por acreditarem no desenho como possibilidade de formação, para além do ensino técnico. 